\title{
Evaluation of patients with Crimean-Congo hemorrhagic fever in Bolu, Turkey
}

*Duran $\mathrm{A}^{1}$, Küçükbayrak A2, Ocak $\mathrm{T}^{1}$, Hakyemez NI², Tap T ${ }^{3}$, Karadað $\mathrm{M}^{4}$, Mengeloðlu $\mathrm{ZF}^{3}$

1. Department of Emergency Medicine, Abant Izzet Baysal University Medical School, Bolu-Turkey

2. Department of Infection Diseases, Abant Izzet Baysal University Medical School, Bolu-Turkey

3. Department of Medical Microbiology, Abant Izzet Baysal University Medical School, Bolu-Turkey

4. Bolu Provincial Directorate of Health, Bolu-Turkey

\begin{abstract}
Background: Crimean-Congo hemorrhagic fever (CCHF), which is associated with a high mortality rate in the Black Sea region of Turkey, has received increasing attention.

Objective: In this study, the epidemiological features, clinical and laboratory findings, treatments, and outcomes of patients diagnosed with CCHF between 2006 and 2012 based on data obtained from the Bolu Provincial Directorate of Health (BPDH) were evaluated.

Methods: BPDH data were reviewed for the period between 1 January 2006 and 31 July 2012. The locations where the tick had attached to the patient, the site of the tick bite on the patient's body, the dates of tick bite and removal, and the demographic characteristics of each patient were recorded. BPDH data on the total number of tick bites, patients with confirmed CCHF, and deaths due to CCHF in Bolu Province during the study period were also evaluated.

Results: A total of 46 patients with CCHF and 38 patients without CCHF but who had been bitten by ticks were admitted to the BPDH. Of the patients with CCHF, $54.3 \%$ were female. The mean age of the patients was $46.88 \pm 2.05$ years (range, 1-79 years). The mortality rate was $8.82 \%$. Patients were predominantly observed in June and July. When the patients were distributed according to their occupations, the majority was houswife (48.6\%), followed by animal husbandry worker $(27.0 \%)$, farmer $(10.8 \%)$, health worker (5.4\%), and other (8.1\%). The symptoms of the patients with CCHF included fatigue $(60.9 \%)$, fever $(60.9 \%)$, and myalgia $(60.9 \%)$. Of those patients with CCHF, $41.3 \%$ were determined to have a high fever.

Conclusions: The probability of developing CCHF decreased as the duration of tick attachment increased. Moreover, although the clinical presentation is important, it is not diagnostic. Physical examination and laboratory findings become more specific in later stages.
\end{abstract}

Keywords: Black Sea, Crimean-Congo hemorrhagic fever virus

African Health Sciences 2013; 13(2): 233 - 242 http://dx.doi.org/10.4314/ahs.v13i2.5

\section{Introduction}

Crimean-Congo hemorrhagic fever virus (CCHFV), which belongs to the genus Nairovirus in the family Bunyaviridae, causes severe disease in humans, with a reported mortality rate of $15-30 \%{ }^{1}$. CrimeanCongo hemorrhagic fever (CCHF) is a viral infection obtained through a tick bite or transmitted through body fluids or the blood of domestic animals or patients with CCHF. It was previously seen in the Crimean Peninsula in $1940^{2}$. It is currently found in 30 countries throughout Africa, Asia, Eastern

*Corresponding author:
Arif Duran
Department of Emergency Medicine
Abant Izzet Baysal University Medical School
14280 Golkoy - Bolu
Turkey
Phone: +90 3742534656
E-mail: drarifduran@gmail.com

African Health Sciences Vol 13 Issue 2 June 2013
Europe, and the Middle East. Patients with CCHF are usually infected through tick bites or contact with blood, fluids, or tissues from viremic humans or other animals ${ }^{3}$. Patients with CCHF may develop fever, bleeding, and death.

Although CCHF had been previously reported in Bulgaria, Iran, and Iraq, no case of CCHF was reported in Turkey until $2002{ }^{4-6}$. PubMed CCHF emerged first in Tokat and Sivas and subsequently spread to other areas ${ }^{7}$. Following a district epidemic in Turkey in 2004, the disease was identified as CCHF by laboratory confirmation, and several reports have since been published ${ }^{8}$. The first case in Bolu, Turkey, was detected in 2008.

Bolu Province, which covers $1.015 \%$ of the area of Turkey $\left(8,276 \mathrm{~km}^{2}\right.$ [827,600 ha]), is located in the western Black Sea region. Approximately 18\% of the Province is comprised of agricultural land. 
Forest covers $59 \%$ of the Province; this represents $2.55 \%$ of the total forest area in Turkey. A total of $15 \%$ of the Province is covered with meadows and pastures. The remaining $8 \%$ of the Province is comprised of nonagricultural lands. The average altitude of the Province is $1,000 \mathrm{~m}$, while the altitude of the city center is around $725 \mathrm{~m}{ }^{9}$. Animal husbandry is common in Bolu. The leather industry is also important; leather is first processed in Gerede, a town in Bolu. It is believed that ticks carrying $\mathrm{CCHFV}$ arrive in Bolu via the leather industry then spread to regions where animal husbandry is common. This hypothesis is supported by the fact that patients presenting with symptoms of CCHF are mostly found in the Gerede region, where leather is the dominant industry (figure 1).

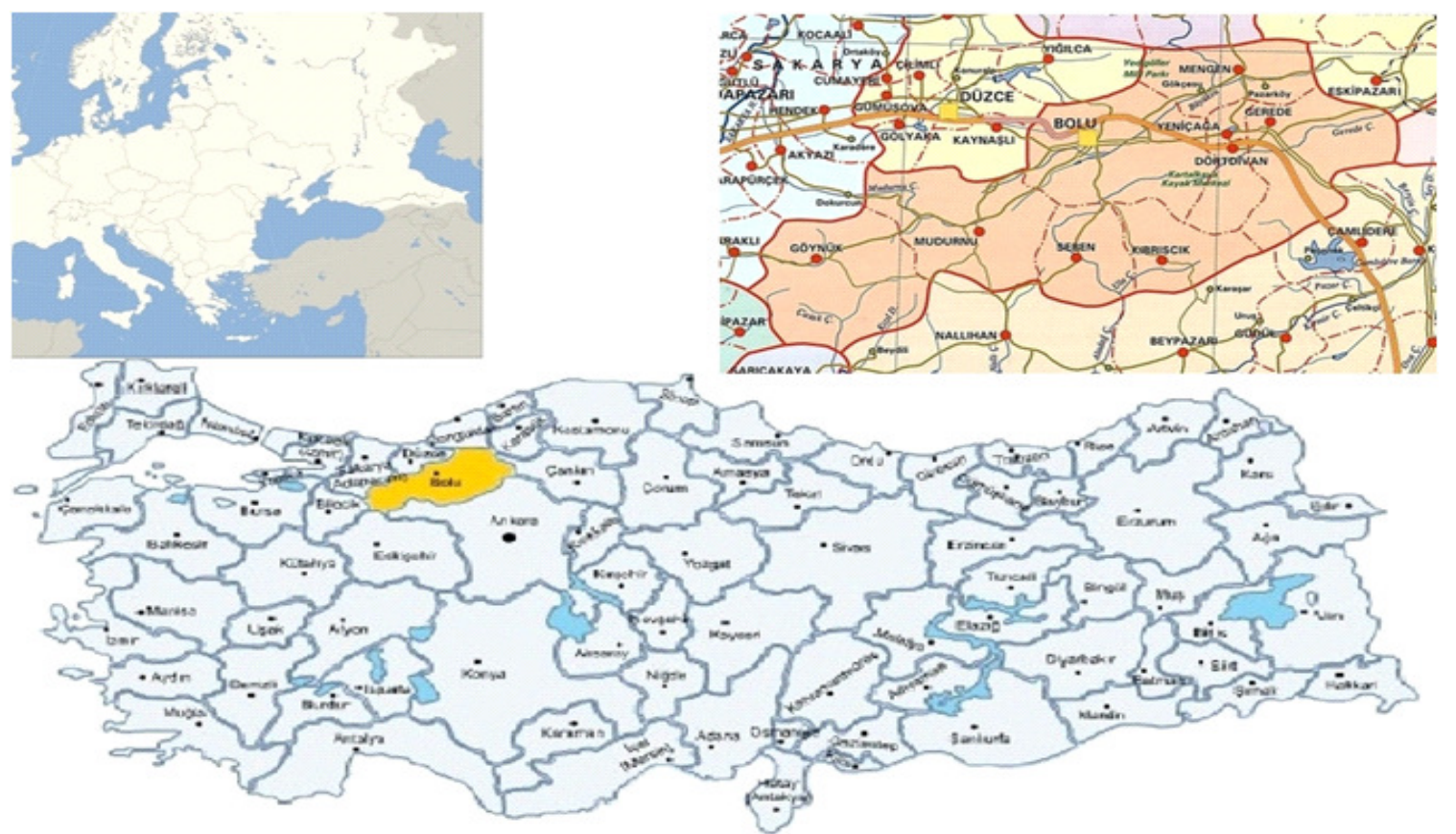

Figure 1: Bolu Providence 332x223mm (72 x 72 DPI)

\section{Methods}

Our study was approved by the Clinical Research Ethics Committee of Abant Izzet Baysal University (Nos. 284 [21 June 2012] and 269 [28 February 2012]). BPDH data were reviewed for patients with confirmed tick attachment and who had been diagnosed with CCHF by blood testing between 1 January 2006 and 31 July 2012.

A total of 12,637 individuals with a history of tick bites or tick contact were found in our region between 2006 and 2012. Among these individuals, the number of patients who were investigated for viral DNA and/or an antibody response with a prediagnosis of CCHF was not known. However, 82 of the individuals whose blood samples were evaluated were considered positive. Data from 46
In this study, patients who presented with a history of tick bites and in whom viral DNA and/or antibody responses had been investigated with a prediagnosis of $\mathrm{CCHF}$ were retrospectively evaluated from the records of the Bolu Provincial Directorate of Health (BPDH). The aim of this study was to compare the presenting symptoms, physical examination findings, laboratory results, and treatment protocols of patients with CCHF with those of CCHF-negative individuals. of these 82 patients and from 38 negative individuals were obtained. These 38 individuals served as the control group.

For the patient and control groups, tick bite data, including clinical, laboratory, and epidemiological findings compatible with CCHF, had been originally recorded on Turkish Ministry of Health surveillance forms. Based on this notification system, epidemiological data were collected, beginning on 1 January 2006, using the standard case reporting forms developed by the CCHF scientific committee. All data were recorded from forms prepared by the Communicable Diseases Department of the BPDH. In the case of missing 
patient information, contact was established with the appropriate city health directorate, and the required information was obtained.

Case definition forms and serum samples obtained from suspected cases (the first sample) are routinely submitted to the Primary Health Care General Directorate, Department of Communicable Diseases, Refik Saydam Hygiene Center (RSHC) Virology Laboratory, by the BPDH. It is required that all patients diagnosed with CCHF based on case definitioncriteria be followed in hospitals. Centers are also directed to collect a second blood sample from individuals with a prediagnosis or definitive diagnosis of CCHF in the second week of the disease or upon discharge, and to send these samples to the BPDH.

Among the cases with epidemiological risk factors and clinical and laboratory findings compatible with CCHF, those with confirmed CCHFV RNA in their blood or body fluid samples by reverse transcriptase-polymerase chain reaction (RT-PCR) evaluation or IgM and/or IgG positivity by ELISA were defined as patients with confirmed CCHF. Risk factors and findings compatible with CCHF were defined as follows:

(1) Epidemiological risk factors: tick bite or tick contact, involvement in animal husbandry or farming, contact with the body fluid of a patient with CCHF or occupation in a laboratory, and individuals with similar complaints in the proximity of a patient with CCHF,

(2) Clinical findings: fever, hemorrhage, headache of acute onset, myalgia/arthralgia, lethargy, nausea/ vomiting, and abdominal pain/diarrhea, and

(3) Laboratory findings: thrombocytopenia (platelet count of $<150 \times 10^{9} / \mathrm{L}$ ) and/or leukopenia (white blood cell count of $<4 \times 10^{9} / \mathrm{L}$ ) with elevated levels of alanine aminotransferase, aspartate aminotransferase, lactate dehydrogenase (LDH), and creatine phosphokinase (CK).

All serum samples were analyzed by the Virology Laboratory of the Refik Saydam Hygiene Center. Patient serum samples were tested for antiCCHF IgM and IgG antibodies by ELISA. The presence of CCHFV RNA was examined by RTPCR, and direct sequence analysis was performed in these centers.

Statistical analyses were conducted using the Statistical Package for the Social Sciences version 17.0 for Windows (SPSS, Inc., Chicago, IL, USA). Mean comparisons for continuous variables were performed using independent-group t-tests. Proportion comparisons for categorical variables were performed using chi-square tests, although Fisher's exact test was used when data were sparse. P-values $<0.05$ were deemed statistically significant.

\section{Results}

According to BPDH records, the numbers of tick bites and contacts increased over time (table 1). Among the patients in this study, $45.7 \%$ were male and $54.3 \%$ were female. The mean age of the patients was $46.88 \pm 2.05$ years (range, 1-79 years). No comparisons could be made between the groups because no data were available regarding age or sex.

Table 1: The distribution of CCHF patients and tick-bite over the years

\begin{tabular}{llll}
\hline & $\begin{array}{l}\text { Tick-bite } \\
\text { or tick } \\
\text { contact }\end{array}$ & $\begin{array}{l}\text { CCHF } \\
\text { patients }\end{array}$ & EXÝTUS \\
\hline 2006 & 147 & 0 & 0 \\
2007 & 3136 & 0 & 0 \\
2008 & 3730 & 23 & 3 \\
2009 & 3115 & 19 & 1 \\
2010 & 895 & 12 & 1 \\
2011 & 860 & 13 & 0 \\
2012 & 811 & 14 & 1 \\
Total & 12694 & 81 & 6 \\
\hline
\end{tabular}

Patients with tick bites presented an average of 2.8 days after finding the ticks.

For both groups, numbers of housewives were higher than other professions. Only two of the patients with CCHF were health care workers. Of these patients one exited and the other survived. The survived one had histories of both tick bite and contact with CCHF patient but the exited one didn't have any histories of contacts with ticks, animals or any CCHF patients. Nine of the patients and seven of the controls didn't give any information about their professions. No statistically significant difference was found between the groups according to professions. Among the patients, the number of people living in rural areas were higher. It was detected that the patients frequently admitted in June and July and the control group frequently admitted in July and August. No significant difference was found between the patients' group and the control group according to admitting month $(\mathrm{p}>0.05)$ (figure 2). 


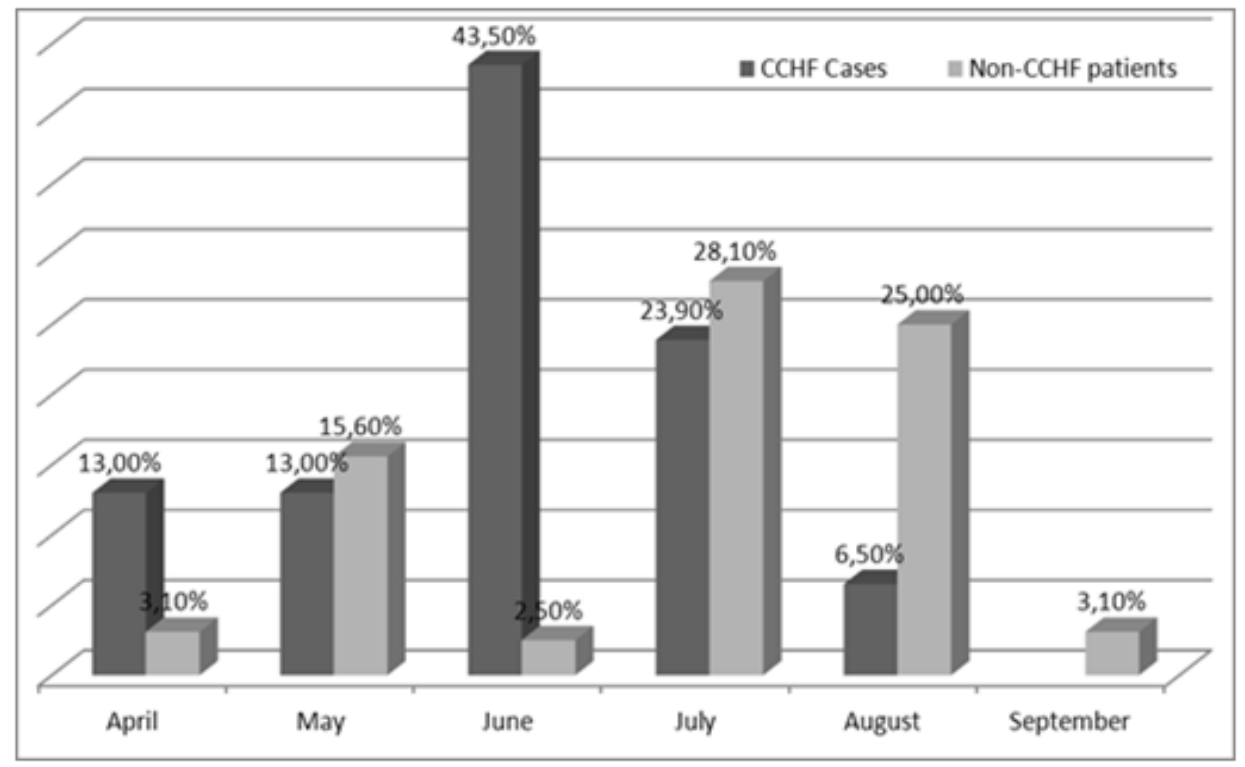

Figure 2: Distribution of the subjects with regard to the month of presentation

Data regarding the risk factors of the groups (tick bite or tick contact, involvement in animal husbandry or farming, contact with the body fluid of a patient with CCHF or working in a laboratory, and individuals with similar complaints in the proximity of a patient with CCHF) are shown in table 2. A significant difference was found between the groups in terms of risk factors $(p<0.05)$. A total of 32 patients had a history of a tick bite, and 14 did not. Of these 32 patients, 30 also had a history of at least one incident of contact with animals or patients or visiting/living in a rural area. A total of 11 of the 14 patients with no history of tick bites had a history of contact with animals. The remaining three patients had a history of visiting rural areas. In 4 of the 32 patients with a history of tick bites, their symptoms began before tick contact; thus, their symptoms were probably dependent on other factors. The number of patients with a history of contact with animals or animal blood was significantly higher than that in the control group $(p<0.05)$. The number of patients with a history of tick bites was higher than that in the control group, but the difference was not statistically significant $(p>0.05)$ (table 2$)$.
The most common complaints in the patient group were fatigue $(84.8 \%)$, fever $(60.9 \%)$, myalgia $(60.9 \%)$, headache $(56.5 \%)$, and nausea $(50 \%)$. In descending order of frequency, vomiting, diarrhea, and abdominal pain were observed. The numbers of patients with headache or diarrhea were significantly higher than in the control group $(\mathrm{p}<0.05)$. Complaints such as fever, myalgia, or fatigue were more frequent in patients with CCHF, but the differences were not significant $(p>0.05)$. One of the patients had no complaints. Three of the controls had no clinical or laboratory findings, but they were investigated because of their histories of visiting rural areas or being in the vicinity of affected patients (table 3).

Among the physical examination findings, only hypotension was significantly more frequent in the patients than in the controls $(\mathrm{p}<0.05)$ (table 3$)$. 
Table 2: The epidemiological characteristics of patients with a diagnosis of Crimean-Congo hemorrhagic fever

\begin{tabular}{|c|c|c|c|}
\hline & CCHF patients & Non-CCHF cases & $\mathbf{P}$ value \\
\hline$\overline{\text { Male }}$ & $16(45,7)$ & - & \\
\hline Female & $19(54,3)$ & 11 & \\
\hline \multicolumn{4}{|l|}{ Age groups (years) } \\
\hline $0-16$ & 3 & - & \\
\hline $17-35$ & 7 & - & \\
\hline $35-50$ & 7 & - & \\
\hline $50-65$ & 10 & - & \\
\hline $65+$ & 7 & - & \\
\hline unknown & 12 & 32 & \\
\hline \multicolumn{4}{|l|}{ Location of residence } \\
\hline Yenicað & 1 & - & \\
\hline Mengen & 5 & - & \\
\hline Mudurnu & 2 & - & \\
\hline Dörtdivan & 2 & - & \\
\hline Gerede & 18 & 2 & \\
\hline City center & 6 & - & \\
\hline unknown & 12 & 30 & \\
\hline \multicolumn{4}{|l|}{ Occupation } \\
\hline Undeclared & 9 & 8 & \\
\hline Farmer & 4 & 3 & \\
\hline Housewife & 18 & 11 & \\
\hline Student or government worker & 2 & 6 & \\
\hline Working in animal husbandry & 8 & 4 & \\
\hline Child $(<16$ years old $)$ & 3 & & \\
\hline Healthcare worker & 2 & & \\
\hline \multicolumn{4}{|l|}{ Risk factores } \\
\hline Living in the countryside & $38(82.6 \%)$ & $25(78.1)$ & \\
\hline Visited the countryside & $35(76.1 \%)$ & $23(71.9)$ & \\
\hline Tick-bite or tick contact & $32(69.6 \%)$ & $16(50 \%)$ & \\
\hline Close contact with animals & $38(82.6 \%)$ & $20(62.5 \%)$ & 0.047 \\
\hline $\begin{array}{l}\text { Contact with animal blood, tissue, } \\
\text { or body fluids }\end{array}$ & $22(47.8 \%)$ & $8(25 \%)$ & 0.043 \\
\hline \multicolumn{4}{|l|}{ The duration } \\
\hline Tick-bite or tick contact time & $6,55 \pm 6,66$ & $13,57 \pm 10,99$ & 0.042 \\
\hline Presenting time & $2,8 \pm 2,29$ & $2,78 \pm 3,53$ & \\
\hline
\end{tabular}

In the patient group, $80.4 \%$ had thrombocytopenia, $78.3 \%$ had leukopenia, $76.1 \%$ showed increased $\mathrm{LDH}$ and liver function test parameters, $67.4 \%$ exhibited an elevation in CK, and $28.3 \%$ had anemia. Among these findings, the frequencies of elevated liver function test parameters $(p<0.001)$, leukopenia $(\mathrm{p}<0.001)$, thrombocytopenia $(\mathrm{p}=0.011)$, and elevation of LDH $(\mathrm{p}<0.009)$ were significantly higher in the patient group than in the control group. Five patients had no complaints. Four of these five patients were prediagnosed with CCHF because of their abnormal laboratory findings. One patient was positive for CCHF, although this patient had no abnormal clinical or laboratory findings (asymptomatic) (table 3). 
Table 3: Possible risk factors for transmission and clinical and laboratory findings in patients with a diagnosis of Crimean-Congo hem

\begin{tabular}{|c|c|c|c|}
\hline & CCHF patients & Non-CCHF & $\mathbf{P}$ \\
\hline & & cases & value \\
\hline \multicolumn{4}{|l|}{ Clinical findings } \\
\hline Fever & $28(60.9 \%)$ & $13(40.6 \%)$ & 0.080 \\
\hline Headache & $26(56.5 \%)$ & $10(31.3 \%)$ & 0.029 \\
\hline Myalgia & $3(6.5 \%)$ & 0 & 0.080 \\
\hline Fatigue & $39(84.8 \%)$ & $22(68.8 \%)$ & 0.094 \\
\hline Nausea & $23(50 \%)$ & $10(31,3 \%)$ & 0.100 \\
\hline Vomiting & $10(21.7 \%)$ & $5(15.6 \%)$ & 0.500 \\
\hline Abdominal pain & $7(15.2 \%)$ & $5(15.6 \%)$ & 0.900 \\
\hline Diarrhea & $9(19.6 \%)$ & $1(3.1 \%)$ & 0.034 \\
\hline Hemorrhagic findings & $6(13 \%)$ & $5(15.6 \%)$ & 0.900 \\
\hline Ecchymosis & $3(6.5 \%)$ & $1(3.1 \%)$ & 0.500 \\
\hline Skin eruption & $7(15.2 \%)$ & $1(3.1 \%)$ & 0.085 \\
\hline Generalized pain & $28(60.9 \%)$ & $13(40.6 \%)$ & 0.080 \\
\hline No clinical findings and symptoms & 1 & 3 & \\
\hline \multicolumn{4}{|l|}{ Examination findings } \\
\hline High Fever & $19(41.3 \%)$ & $9(28.1 \%)$ & 0.240 \\
\hline Consciousness Disorders & $3(6.5 \%)$ & $1(3.1 \%)$ & 0.330 \\
\hline Gingival Bleeding & $4(8.7 \%)$ & $2(6.3 \%)$ & 0.960 \\
\hline Hypotension & $9(19.6 \%)$ & $1(3.1 \%)$ & 0.034 \\
\hline Tachycardia & $6(13.0 \%)$ & $1(3.1 \%)$ & 0.130 \\
\hline Epistaxis & $2(4.3 \%)$ & $2(6.3 \%)$ & 0.710 \\
\hline Splenomegaly & $3(6.5 \%)$ & - & 0.140 \\
\hline Ecchymosis & $3(6.5 \%)$ & $1(3.1 \%)$ & 0.510 \\
\hline Hematuria & $4(8.7 \%)$ & $1(3.1 \%)$ & 0.330 \\
\hline Maculopapular Rash & $6(3.1 \%)$ & $1(3.1 \%)$ & 0.130 \\
\hline Vaginal Bleeding & $4(8.7 \%)$ & $2(6.3 \%)$ & 0.690 \\
\hline Gastro Ýntestinal tract bleeding & $1(2.2 \%)$ & $1(3.1 \%)$ & 0.790 \\
\hline \multicolumn{4}{|l|}{ Laboratory findings } \\
\hline Leukopenia & $36(78.3 \%)$ & $12(37.5 \%)$ & 0.001 \\
\hline Thrombocytopenia & $37(80.4 \%)$ & $17(53.1 \%)$ & 0.011 \\
\hline Elevated AST and ALT & $35(76.1 \%)$ & $11(34,4 \%)$ & 0.001 \\
\hline Elevated LDH & $35(76.1 \%)$ & $15(46.4 \%)$ & 0.009 \\
\hline Elevated CK & $31(67.4 \%)$ & $15(46.4 \%)$ & 0.072 \\
\hline
\end{tabular}

Ribavirin and supportive care were given to the patients until the test results were obtained and the disease had been detected. A total of 33 patients and 7 controls were given ribavirin. The difference between the numbers of individuals taking ribavirin was significant $(p<0.001)$. Only 10 patients needed suspensions of platelets, fresh frozen plasma, or erythrocytes. Eight controls were given supportive treatment. No difference was found between the groups in terms of supportive care treatments $(p>$ 0.05) (table 4).

A total of 31 patients were admitted with symptoms and prehemorrhagic stage findings. Of 12 patients admitted with hemorrhagic stage findings, 10, 4, and 3 presented with bleeding, consciousness disturbances, and splenomegaly, respectively.
Table 4: The prognosis and treatment of patients with a diagnosis of Crimean-Congo hemorrhagic fever

\begin{tabular}{llcc}
\hline & CCHF & Non-CCHF & P \\
& patients & cases & value \\
\hline $\begin{array}{l}\text { Referred another } \\
\text { center }\end{array}$ & $1(2.2 \%)$ & $1(3.1 \%)$ & \\
Cured & $3(6.5 \%)$ & $3(\%)$ & \\
Died & $2(4.3 \%)$ & 0 & \\
Ribavirin & $33(71.7 \%)$ & $6(\%)$ & $<0.001$ \\
Supportive & $15(33.7 \%)$ & $10(\%)$ & 0.9 \\
\hline
\end{tabular}




\section{Discussion}

In Turkey, CCHF was first reported in 2002. The first case in Bolu, which is located in the Black Sea region, was detected in 2008. No data on tick bites or contacts is available between 2002 and 2006. The numbers of tick bites and contacts have increased since 2006.

Most outbreaks of CCHF have been reported in Iran ${ }^{10}$, Pakistan ${ }^{11}$, Bulgaria ${ }^{4}$, and Turkey ${ }^{12-14}$. A total of 1,820 cases of CCHF were reported in Turkey between 2002 and 2007 (150 in 2002-2003, 249 in 2004, 266 in 2005, 438 in 2006, and 717 in $2007)^{15}$. After the numbers of tick contacts and cases peaked, increased awarenessamong healthcare workers and society is considered to be the reason for the decrease in incidence of this disease.

The numbers of male and female CCHF patients in Turkey are similar. People living in and actively working in rural areas are particularly subject to this disease. Two-thirds of patients are housewives or farmers. In Turkey, housewives living in rural areas work actively, particularly in agriculture and animal husbandry ${ }^{16-20}$. Among the patients from our region, $53 \%$ were female while $47 \%$ were male. Nine of the patients gave no information about their profession. Fifty-seven percent of the remaining patients were housewives or farmers. Among the patients, $83 \%$ lived in rural areas.

Most cases in Turkey are observed between March and September, with a peak in June and July. The intensity of work in agriculture and animal husbandry during these months may be an important factor leading to the peak in cases ${ }^{21}$. All patients in our study were admitted between April and August, and the most frequent cases occurred in June and July $(67.2 \%)$. In our region, the temperature becomes warmer later and cooler earlier due to the altitude. In addition, those patients with a prediagnosis of CCHF but with negative tests were mostly admitted in July and August.

$\mathrm{CCHF}$ is mostly community-acquired. The basic modes of transmission are contact with ticks, contact of the skin or mucosa with blood or other animal tissues, and drinking nonpasteurized milk. Some cases in Russia have been said to involve transmission via aerosols, but no evidence had been found to support this hypothesis ${ }^{22}$. In Turkey, $70 \%$ of affected patients have a history of tick contact. Similarly, $70 \%$ have a history of contact with blood or other animal tissues ${ }^{23-25}$. In our region, $69.6 \%$ of the patients had a history of tick contact, $82.6 \% \mathrm{had}$ a history of animal contact, and $47.8 \%$ had a history of animal blood contact. The frequency of a history of animal contact in patients with CCHF was higher in our region compared with data from all of Turkey. As reported in the literature, nosocomial transmission may occur. The risk of transmission to hospital staff is high, particularly after contact with individuals who are not known to be infected with CCHFV when they are first admitted to the hospital. For this reason, we propose that hospital staff working in endemic regions should treat newly admitted individuals as potential CCHF patients until $\mathrm{CCHF}$ is ruled out ${ }^{26}$. Globally, this disease was detected in only about 80 healthcare workers until $2006{ }^{27}$. The incidence among hospital staff is very low in Turkey ${ }^{21}$. In our region, only two of the patients were healthcare workers, and one of them died. That patient had no history of contact with ticks, animals, or other patients with CCHF, whereas the patient who survived had a history of contact with ticks and another patient with CCHF.

The manifestation of the disease is divided into four phases: the incubation period, prehemorrhagic stage, hemorrhagic stage, and convalescent phase. The incubation period is 3-7 days long, and varies according to the route and source of transmission and viral load $(1-10)$ viruses are sufficient for development of the disease $)^{26,27}$. Only one patient in our study had no complaints; thispatient had no abnormal clinical or laboratory findings. The prehemorrhagic stage is characterized by symptoms similar to those seen during the prodromal period of other viral infections ${ }^{29}$. Thirty-one of our patients presented with symptoms and findings of the prehemorrhagic stage. In the hemorrhagic stage, which is usually short and rapidly progressive, petechia, conjunctival hemorrhaging, epistaxis, hematemesis, hemoptysis, melena, and, in some patients, hepatosplenomegaly can be seen ${ }^{12,14,16}$. In our study, 14 patients had hemorrhagic stage findings. About $40-60 \%$ of patients in this phase die. In most cases, multiorgan failure, DIC, and death as a result of shock occur ${ }^{30,31}$. Of 68 patients with $\mathrm{CCHF}$ (data were obtained for 46), 6 in our region died; data for 2 of these 6 patients were obtained. The mortality rate in our region was $8.8 \%(6 / 68)$. The convalescent period starts 10-20 days after the onset of the disease in patients who survive ${ }^{26}$. Approximately $67 \%$ of the 46 CCHF-diagnosed patients whose data were obtained by us were admitted with symptoms and prehemorrhagic stage 
findings; a total of $30.4 \%$ were admitted with hemorrhagic stage findings.

The most common complaints in affected patients in Turkey are fatigue, fever, myalgia, and muscle pain ${ }^{21}$. The most common complaints reported in the literature are fever, fatigue, headache, loss of appetite, and myalgia ${ }^{16,23,32-34}$. Approximately $25 \%$ of affected patients in Turkey show hemorrhagic findings. Over the years, a decrease in this ratio has been reported ${ }^{21}$. The most common symptoms in our patients were fatigue (84.8\%), fever $(60.9 \%)$, myalgia $(60.9 \%)$, headache $(56.5 \%)$, and nausea $(50 \%)$. Vomiting, diarrhea, and abdominal pain were observed in descending order of frequency. Ecchymoses, rash, and bleeding were seen at frequencies of $6.5,15.2$, and $13 \%$, respectively.

The most common laboratory findings reported in patients with $\mathrm{CCHF}$ are thrombocytopenia, leukopenia, and elevated liver function parameters 4 , 14, 16, 23, 24. In Turkey, 93.2\% of the cases reportedly had thrombocytopenia, 88.9\% had leukopenia, and $85.9 \%$ had elevated liver function parameters. Among our patients, $80.4 \%$ had thrombocytopenia, $78.3 \%$ had leukopenia, $76.1 \%$ had elevated liver function parameters and $\mathrm{LDH}$, $67.4 \%$ had elevated CK, and $28.3 \%$ had anemia. In this study, the frequencies of elevated liver function parameters $(p<0.001)$, leukopenia $(p<0.001)$, thrombocytopenia $(\mathrm{p}<0.011)$, and elevated LDH $(\mathrm{p}<0.009)$ were significantly higher than in the control group.

An early diagnosis is essential to reduce patient mortality, especially in the early phase (prehemorrhagic stage). For this reason, a history of travel to endemic regions, tick exposure, and contact with blood or body fluids from humans or other animals should be questioned. The most important diagnostic method is isolation of the virus by in vitro cell culture ${ }^{35}$. Viral isolation is useful only in the early phase of infection when the viral load is high, but it suffers from poor sensitivity; moreover, virus isolation can only be performed if biosafety level 4 containment facilities are available. In Turkey, RSHC is the only reference laboratory able to perform cell cultures for the isolationof CCHFV. For this reason, none of the patients in our study were diagnosed by this method. The other method available for the diagnosis of CCHF is detection of the viral genome. Real-time PCR is advantageous because of its low contamination rate, high rates of sensitivity and specificity, and availability of results within several minutes ${ }^{26,35}$. Unfortunately, viremia is limited to within the first 9 days of infection. Therefore, serologic tests should be performed in suspected cases. Serological tests are useful in the second week of the disease. Today, ELISAs are performed to detect $\mathrm{IgM}$ and $\mathrm{IgG}$ antibodies in serum. Both antibodies can be detected in blood within about 7 days of the onset of the disease ${ }^{36}$. A specific IgG response can be detected until the 5 th postinfective year, while $\operatorname{IgM}$ can be detected until the 4th postinfective month with this method ${ }^{28}$. Therefore, IgM is useful to demonstrate a present infection, while IgG shows a past infection. At the RSCH, blood samples are first tested by real-time PCR for presence of the viral genome, and then serologically to determine the antibody titer if a negative result is obtained. Our patients were diagnosed using one of these methods.

The basic treatment for CCHF aims to correct fluid and electrolyte imbalances and eliminate clinical manifestations. Early diagnosis and replacement treatments such as blood, platelets, and plasma may be life-saving, particularly for patients in the hemorrhagic stage ${ }^{37,38}$. Early antiviral treatment (ribavirin) is recommended by the $\mathrm{WHO}^{39}$. Only 10 of our patients required at least one replacement treatment including suspensions of platelets, fresh frozen plasma, as erythrocytes or supportive treatment. Early ribavirin treatment is associated with increased survival rates, shorter recovery times, and the faster normalization of laboratory parameters ${ }^{16}$ - Ribavirin therapy is especially recommended for suspicious cases ${ }^{40}$ and healthcare workers suspected to have been contaminated ${ }^{41}$. However, the benefit of the use of ribavirin is still controversial. Studies on this topic are mostly retrospective, and their methodologies are inadequate ${ }^{42}$. In a randomized study by Köksal et al. ${ }^{43}$, no effects of ribavirin were found on clinical and laboratory findings or mortality. In a systematic review and meta-analysis by Ascioglu et $a l^{44}$, ribavirin reportedly had no effects on mortality, clinical recovery, shorter hospital stay, earlier recovery of laboratory findings, or a decreased need for blood products.

In our study, 33 patients and 7 controls were given ribavirin treatment, and a significant difference was found $(p<0.001)$. Ten of these patients were given supportive treatment with at least one of the following suspensions: platelets, fresh frozen plasma, or erythrocytes. Eight controls underwent such treatment. The difference was not significant $(\mathrm{p}>$ 0.05). In our study, the criteria for initiation of ribavirin therapy were based more on laboratory 
results than on clinical findings. The significant differences, especially in the laboratory findings between the patient and control groups, were reflected in the values for treatment initiation.

\section{Conclusion}

Occupation and visiting rural areas are important factors involved in contact with ticks in terms of the transmission of CCHF. Tick bites, contact with animals, being in the vicinity of a patient with CCHF, or being a healthcare worker is not absolutely necessary for transmission of the infection. The probability of disease decreases as the duration of tick attachment increases. If the tick carries the CCFHvirus, it may infect the susceptible individuals between the time periods of 3 to 13 days ${ }^{45}$. If not, whatever the tick contact time is, the person will not have the disease. Moreover, the clinical presentation is important, but it is not diagnostic; physical examination and laboratory findings become more specific in later stages. Ribavirin therapy is an effective treatment option, but supportive treatment appropriate to the patient should not be ignored. Public awareness about CCHF has decreased the incidence of the disease.

\section{References}

1. Swanepoel R, Gill DE, Shepherd AJ, Leman PA, Mynhardt JH, Harvey S. The clinical pathology of Crimean-Congo hemorrhagic fever. Rev Infect Dis 1989; 11:794-800.

2. Chris A. Whitehouse. Crimean-Congo hemorrhagic fever. Antiviral Research. 2004; 64(3): 145-60

3. Khan AS, Maupin GO, Rollin PE, Noor AM, Shurie HH, Shalabi AG, et all. An outbreak of Crimean-Congo hemorrhagic fever in the United Arab Emirates. Am J Trop Med Hyg 1997;57:51925.

4. Papa A, Christova I, Papadimitriou E, Antoniadis A. Crimean- Congo hemorrhagic fever in Bulgaria. Emerg Infect Dis 2004; 10: 1465 67.

5. Alavi-Naini R, Moghtaderi A, Koohpayeh HR, Sharifi-Mood B, Naderi M, Metanat M, et all. Crimean-Congo hemorrhagic fever in Southeast of Iran. J Infect 2006;52:378-82.

6. S. K. Al-Tikriti, F. Al-Ani, F. J. Jurji, H. Tantawi, M. Al-Moslih, N. Al-Janabi, et all. Congo/ Crimean haemorrhagic fever in Iraq. Bull World Health Organ 1981;59:85-90.

7. Gunes T, Engin A, Poyraz O, Elaldi N, Kaya S,

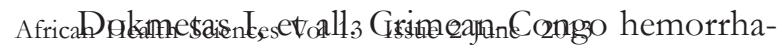

gic fever virus in high-risk population, Turkey. Emerg Infect Dis. 2009; 15(3): 461 -64.

8. Ergonul O, Zeller H, Celikbas A, Dokuzoguz B. The lack of Crimean-Congo hemorrhagic fever virus antibodies in healthcare workers in an endemic region. Int J Infect Dis 2007; 11:4851.

9. http://www.bolu.gov.tr/documents/ genel_bilgiler.pdf29

10. Sharifi Mood B, Alavi-naini R, Metanat M. Ten years after the beginning of Crimean-Congo hemorrhagic fever outbreak in Iran: A promising report. Iran J Clin Infect Dis. 2009;4:189-93

11. Azeem S. Sheikha, Aqleem A. Sheikhb, Nadeem S. Sheikhc, Rafi-U-Shand, Mohammad Asife, Farhan Afridie, et all. Bi-annual surge of Crimean-Congo haemorrhagic fever (CCHF): A five-year experience. Int J Infect Dis. 2005;9:3742

12. Ergonul O, Celikbas A, Dokuzoguz B, Eren S, Baykam N, Esener H. Characteristics of patients with Crimean-Congo hemorrhagic fever in a recent outbreak in turkey and impact of oral ribavirin therapy. Clin Infect Dis. 2004;39:284-87

13. Karti SS, Odabasi Z, Korten V, Yilmaz M, Sonmez M, Caylan R, et all. Ksiazek. CrimeanCongo hemorrhagic fever in Turkey. Emerg Infect Dis. 2004;10:1379-84

14. Bakir M, Ugurlu M, Dokuzoguz B, Bodur H, Tasyaran MA, Vahaboglu H. Crimean-Congo haemorrhagic lever outbreak in Middle Anatolia: A multicentre study of clinical features and outcome measures. J Med Microbiol. 2005;54:38589

15. Yilmaz GR, Buzgan T, Irmak H, Safran A, Uzun $\mathrm{R}$, Cevik MA, et all. The epidemiology of Crimean-Congo hemorrhagic fever in Turkey, 2002-2007. Int J Infect Dis. 2009;13(3):380-86

16. Ozkurt Z, Kiki I, Erol S, Erdem F, Yýlmaz N, Parlak M, et all. Tasyaran Crimean-Congo hemorrhagic fever in Eastern Turkey: Clinical features, risk factors and efficacy of ribavirin therapy. J Infect. 2006;52:207-15

17. Vorou R, Pierroutsakos IN, Maltezou HC. Crimean-Congo hemorrhagic fever. Curr Opin Infect Dis 2007;20:495-500.

18. Cevik MA, Uzun R, Yilmaz N, Ugurlu M, Elaldi $\mathrm{N}$, Bodur $\mathrm{H}$, et all. Risk factors for CrimeanCongo haemorrhagic fever outbreak in Central Anatolia: a case control study. R2227. 15th European Congress of Clinical Microbiology and Infectious Diseases (ECCMID). 2005. 
19. Swanepoel R, Shepherd AJ, Leman PA, Shepherd SP, Miller GB. A common-source outbreak of Crimean-Congo haemorrhagic fever on a dairy farm. S Afr Med J 1985;68:635-37.

20. Izadi S, Holakouie-Naieni K, Majdzadeh SR, Chinikar S, Nadim A, Rakhshani F, et all. Seroprevalence of Crimean-Congo hemorrhagic fever in Sistan-va-Baluchestan Province of Iran. Jpn J Infect Dis 2006;59:326-28.

21. Yilmaz GR, Buzgan T, Irmak H, Safran A, Uzun $\mathrm{R}$, Cevik MA, et al. The epidemiology of CrimeanCongo hemorrhagic fever in Turkey, 2002-2007. Int J Infect Dis. 2009;13(3):380-86.

22. Watts DM, Ksiazeck TG, Linthicum KJ, Hoogstraal H. Crimean-Congo hemorrhagic fever. In: Monath TP, editor. The Arboviruses: Epidemiology and Ecology. Florida: CRC Press; 1988:177-222

23. Whitehouse CA. Crimean-Congo hemorrhagic fever. Antivir Res 2004;64:145-60.

24. Schwarz TF, Nsanze A, Ameen AM. Clinical features of Crimean-Congo haemorrhagic fever in the United Arab Emirates. Infection 1997;40:36467.

25. Hoogstraal H. The epidemiology of tick-borne Crimean-Congo haemorrhagic fever in Asia, Europe and Africa. J Med Entomol 1979;15:307417

26. Suma B. An Update on Crimean Congo Hemorrhagic Fever. J Glob Infect Dis. 2011; 3(3): 285-92.

27. David R. Franz, Peter B. Jahrling, Arthur M. Friedlander, David J. McClain, David L. Hoover, W. Russell Bryne, et all. Clinical recognition and management of patients exposed to biological warfare agents. JAMA. 1997;278:399-411

28. Ergönül O. Crimean-Congo haemorrhagic fever. Lancet Infect Dis. 2006;6:203-14

29. Hoogstraal H. The epidemiology of tick borne Crimean-Congo hemorrhagic fever in Asia, Europe and Africa. J Med Entomol. 1979;15:307417

30. Sannikova IV, Pacechnikov VD, Maleev VV. Respiratory lesions in Crimean-Congo hemorrhagic fever. Ter Arkh. 2007;79:20-23.

31. Doganci L, Ceyhan M, Tasdeler NF, Sarikayalar $\mathrm{H}$, Tulek N. Crimean-Congo hemorrhagic fever and diffuse alveolar haemorrhage. Trop Doct. 2008;38:252-54

32. Alavi-Naini R, Moghtaderi A, Koohpayeh HR, Sharifi-Mood B, Naderi M, Metanat M, et all. Crimean-Congo hemorrhagic fever in Southeast of Iran. I Infect 2006;52:378-82

33. Peters CJ, Bunyaviridae. California encephalitis. Hantavirus pulmonary syndrome andbunyavirid hemorrhagic fevers. In: Mandell GL, Bennett JE, Dolin R, editors. Principles and practice of infectious diseases. 6th ed. Philadelphia: Churchill Livingstone; 2005. p. 2086-90.33

34. Swanepoel R, Gill DE, Shepherd AJ, Leman PA, Mynhardt JH, Harvey S. The clinical pathology of Crimean-Congo hemorrhagic fever. Rev Infect Dis 1989;11(Suppl 4):S794-800.

35. Dowall SD, Richards KS, Graham VA, Chamberlain J, Hewson R. Development of an indirect ELISA method for the parallel measurement of $\operatorname{IgG}$ and IgM antibodies against Crimean-Congo haemorrhagic fever $(\mathrm{CCHF})$ virus using recombinant nucleoprotein as antigen. J Virol Methods. 2012;179:335-41

36. Shepherd AJ, Swanepoel R, Leman PA. Antibody response in Crimean-Congo hemorrhagic fever. Rev Infect Dis. 1989;11 Suppl 4:S801-06.

37. Bossi P, Van Loock F, Tegnell A, Gouvras G; Task Force on Biological andChemical Agent Threats, Public Health Directorate, European Commission, Luxembourg. Bichat clinical guidelines for bioterrorist agents. Euro Surveill. 2004;9(12):E1-2.

38. Borio L, Inglesby T, Peters CJ, Schmaljohn AL, Hughes JM, Jahrling PB, et all. Working Group on Civilian Biodefense. Hemorrhagic fever viruses as biological weapons: medical and public healthmanagement. JAMA. 2002;287(18):2391405.

39. World Health Organization. Crimean-Congo haemorrhagic fever.Fact sheet 208. Geneva: World Health Organization; 2001. Available at: http://www.who.int/mediacentre/factsheets / fs208/en/.(accessed May 2009)

40. Centers for Disease Control and Prevention (CDC). Update: management of patients with suspected viral hemorrhagic fever-United States. MMWR Morb Mortal Wkly Rep 1995; 44:475-79.

41. Smego Jr RA, Sarwari AR, Siddiqui AR. CrimeanCongo hemorrhagic fever: prevention and control limitations in a resourcepoor country. Clin Infect Dis 2004;38:1731-35

42. Ascioglu S, Elaldi N, Bodur H, Vahaboglu H, Leblebicioglu H. Response to Doganci J Infect 2009;59: 290-91

43. Koksal Ý, Yilmaz G, Aksoy F, Aydin H, Yavuz Ý, Iskender S, et all. The efficacy of ribavirin in the treatment of Crimean-Congo hemorrhagic fever in Eastern Black Sea region in Turkey.J Clin Virol 2010;47:65-68

44. Ascioglu S, Leblebicioglu H, Vahaboglu H, Chan KA. J Antimicrob Chemoher 2011;66:1215-22

45. Kandis H, Katirci Y, Baltaci D, Saritas A, Kara IH, Geyik MF. Investigation of Clinical and Laboratory Findings of 26 Cases with CrimeanCongo Hemorrhagic Fever. Biomedical Research, 2012; 23 (4): 589-95 